\title{
Comparative Study on Characteristics and Models of Regional Innovation Resource Allocation
}

\author{
Chao ZENG ${ }^{1}$, Yi ZHOU ${ }^{2, a}$, Yunqin ZOU ${ }^{3}$ \\ 1 Jiangxi Normal University Science and Technology College,China \\ 2 Jiangxi Normal University Business College, China \\ 3 Jiangxi Normal University Chemical and Chemical engineering College, China \\ a jxsdjh@vip.sina.com
}

Keywords: Regional, innovative resource allocation, characteristics, model comparison

\begin{abstract}
Under the background of the deep adjustment of the world economy and the new normal of the domestic economy, under the new proposition of supply-side structural reform, it is particularly important to improve China's innovative resource allocation model. Innovative resources, like other general resources, are not self-contained in the process of resource allocation. They must be based on the role of a certain mechanism to form a configuration pattern unique to a certain period of time in line with the current state of economic and social development. In the modern economic society, enterprises attach importance to the integration of domestic and foreign innovative resources model allocation is an effective shortcut to enhance innovation capabilities, and innovation resource allocation is driven by market-driven, government-driven and social-driven. Based on the relevant literatures, this paper summarizes the basic models of China's innovation resource allocation, and strives to explore the path model for the optimization of China's innovation resources.
\end{abstract}

\section{Introduction}

The concept of innovative resources is based on the concept of "resources" and is different from resources in the general sense, with its own connotation and characteristics. Innovative resources refer to the various inputs of enterprise technological innovation, including input factors of human, material and financial resources. These are both commodities that need to flow and important resources that need to be protected. Various technological innovation resources are limited.

\section{Classification of innovative resources}

\subsection{Innovative human resources}

Innovative human resources are the part of human resources that is closely linked to innovation. It is the part of human resources that has the ability to learn, apply and create knowledge and engage in innovation-related work. Innovative human resources are different from ordinary human resources. After the large-scale automated production is promoted, human resources are gradually losing their main position in the production process, replaced by other resources such as material resources and information resources, and innovative human resources are The importance of the production process is becoming increasingly prominent. The creation of knowledge, the transformation of innovation results, and the application of marketization all depend on the ingenuity of innovative human resources. At present, the common indicator used to measure the amount of innovative human resources in a country is the number of research and development activities, mainly including those engaged in three types of innovation activities: basic research, applied research and experimental development. 


\subsection{Innovative financial resources}

Innovative financial resources refer to funds that can effectively support regional innovation activities. Under the rapid development of science and technology, high investment in innovative financial resources has become a necessary guarantee for the smooth development of innovative activities. The source, quantity and structure of innovative financial resources input will directly affect the scale, process and level of innovation activities, thus affecting the overall innovation capability of the region. The quantity, source channels and distribution ratio of innovative financial resources directly determine and influence the scale and nature of innovation activities. The source structure of innovative financial resources determines the role of innovation entities in promoting the development of regional innovation capabilities.

\subsection{Innovative material resources}

Innovative material resources refer to all tangible material resources used for innovation activities and are the fundamental material guarantee for innovation activities. The quantity and quality of innovative material resources are constantly improving with the deepening of regional innovation and development. The types of material resources are more abundant, and various scientific research instruments related to innovation activities have become more sophisticated. The extensive use of instruments, equipment, laboratories and scientific research institutions belonging to universities, enterprises and scientific research institutions has effectively improved the efficiency of innovation.

\subsection{Innovative technical resources}

Innovative technology resources refer to the various technical resources that the main body of scientific and technological innovation collects, organizes and stores internally or externally to ensure the successful completion of scientific and technological innovation activities. It is a resource that exists in the form of knowledge and is one of the main manifestations of innovation achievements. From the introduction of innovative ideas to research and development to commercial applications, the entire process needs to be supported by innovative technologies. Throughout the innovation process, a series of complex factors will be designed to interfere and influence, so even if there is anticipation and planning. However, the process of innovation still presents great uncertainty. To overcome various uncertainties and make scientific and reasonable predictions and judgments, it is inseparable from the use of information resources. Innovative technology resources mainly include patent applications, technology market turnover, etc. Innovative technology resources can continue to enrich content and improve quality as innovation activities continue to deepen.

\section{Analysis of the characteristics of innovative resource allocation}

\subsection{Energy efficiency of innovative resource allocation}

As a resource, innovative resources are resources that have been utilized by human society. To obtain innovative resources, some competitive behaviors are needed. However, the objective existence of regional innovation system resources does not mean that the system resources can naturally be in the best configuration state and exert maximum effectiveness. The existence of resources is not simply equivalent to the effective role of resources. The result of competition is nothing more than the distribution of innovation resources by various subjects, but the distribution behavior itself does not consider whether the allocation efficiency of innovation resources is optimal, that is to say, the efficiency of innovation resources is different when different innovation entities carry out innovation activities. Therefore, for the regional economy, the effective allocation and role of resources is more important than the existence of resources.

\subsection{Time domain of innovative resource allocation}

Innovation is the aggregation of resources of reality and potential. The existing leading technology is the result of the accumulation of past research and development activities, reflecting a stock release. 
The achievements of basic scientific research today are also new development potentials for the future. The time domain of the role of this innovative resource reflects the procedural nature of the role of innovative resources, and also illustrates the necessity of research on the allocation of innovative resources. From the innovation activity itself, it is the process of outputting innovation results through the use of innovative resources by the innovation subject. After the output of the innovation results, the innovation results at this time will become the innovation resources in the future innovation activities. This new round The innovative resources may be innovative knowledge resources, innovative material resources or innovative information resources. From the above perspective, innovative resources can be continuously updated and accumulated, that is to say, the most cutting-edge technology available is obtained through the release of the stock of past innovations, and the stock of innovation released is the allocation of innovative resources. To decide.

\subsection{Scarcity of innovative resource allocation}

Scarcity is the essential attribute of innovation resources as resources. The demand for resources is unlimited. This is still effective between innovation subjects and innovation resources. Although innovative resources are renewable, they are not freely available anytime, anywhere. Innovative financial resources and innovative human resources are indispensable in the process of innovation activities for innovation entities, but because the resources owned by the innovation entities cannot meet the conditions for the development of innovation activities, although the institution wants to obtain unlimited financial resources and Human resources, but it is impossible to obtain unlimited resources as they wish.

\subsection{Regionalization of innovative resource allocation}

Innovative resource allocation has significant regional characteristics. Due to the different levels of economic development, scientific and technological development, and technological development conditions in various regions of China, regional economies with different leading industries have gradually formed certain weak links in the allocation of innovative resources, adjusted and improved, and reduced the flow of innovative resources. And the obstacles to operation, expand the scale of innovative resources, improve the management of innovative resources, and promote a virtuous cycle of technological, economic and social development in the region.

\section{Analysis on the Mode of Regional Innovation Resource Allocation in China}

\subsection{Market-driven innovation resource allocation model}

The basic mode of operation of the market economy is the voluntary trading and competition between diversified stakeholders for the motivation of maximizing their respective interests. This process of operation always motivates each stakeholder with the increase in marginal profit of the new structure. With the continuous deepening of economic system reform and the continuous improvement of the market system, the intensity of using market power to allocate resources in various regions and fields in China is also constantly strengthening. In the field of production and management, in the field of research and development of scientific and technological achievements, the market driving force is already occupying a dominant position. The level of marketization in a region and the maturity of the market also greatly affect the ability to allocate innovative resources.

\subsection{Government-driven innovation resource allocation model}

In the economic operation system, in order to effectively allocate scarce resources, solve the problems of public resource construction and market inefficiency, and promote healthy and sustainable economic development, the government must play its irreplaceable role and commit to the order and system construction of innovative behavior. The key to economic growth lies in institutional factors. The government must formulate laws and regulations, supervise the market order, protect and safeguard intellectual property rights, coordinate the interests of different 
innovation entities, establish market order and rules, and improve the supervision mechanism. By concentrating social forces, decentralizing and reducing innovation risks, and increasing the success rate of innovation, various innovative resources can be organically integrated in regional economic development. By setting an effective guarantee mechanism, the interests of innovation activities are protected by law.

\subsection{Socially driven innovative resource allocation model}

Social drive refers not only to the social atmosphere and the role of various non-governmental organizations in the allocation of resources, but also to the social trends and the various non-institutional links and the power of network allocation. The social atmosphere is the role of various social aspirations, ideas and trends in social progress. Governments, social organizations, and enterprise organizations all correct their own actions for the pressure of mitigating social contradictions. This is an objective force for social progress and a social and human environment that cannot be lacked in the process of institutional perfection.

\section{Summary}

Due to the influence of China's economic and social development history, the pattern of resource allocation in China is quite special. We must handle the relationship between the government and the market and strengthen the organic coordination and cooperation between the two. It is necessary to rely on the market, the "invisible hand", to make the market play a decisive role, but at the same time, to better play the role of the government, because the market can not solve all problems, the market needs the government to provide rules and environment for the market, and The government needs to provide the necessary protection for the vulnerable groups in the market. The transition period also requires the government to provide effective guidance and promotion for the healthy development of the economy. Only through market, government, and social-driven cooperation can we achieve a more optimal allocation of innovative resources to promote economic and social health and effective development.

\section{Acknowledgement}

This paper is one of the research results of Research on the Difference of Enterprise Innovation Resource Allocation System under Supply Side Reform in the Research project of Humanities and Social Sciences in Universities in Jiangxi Province.

\section{References}

[1] S.K. Zhao and D.W. Zhang. Research on the optimal allocation mode of scientific and technological information resources for regional innovation. Library and Information Work, vol.03, pp. 40-46,2015.

[2] H.H. Yuan and N. Jin. Beijing-Tianjin-Hebei innovation resource allocation efficiency evaluation and promotion research. J. Looking around the Bohai Sea economy, vol.06, pp. 06-16,2016.

[3] B.Y. Xiao. Research on resource allocation efficiency of agricultural science and technology innovation in China based on DEA model . Journal of Jilin Agricultural Science and Technology College, vol.04, pp. 62-65, 2016. 